\title{
Boxes, Figures, and Tables
}

BOXES

1.1 The Multiple Tools of U.S. Housing Policy 20-21

3.1 Origins: Laws Passed or Lives Touched? 65-66

7.1 Other Seniors' Groups 133-34

10.1 American Exceptionalism in Decline 195-96

FiguRES

6.1 Support for Social Policy by Party Identification 120

7.1 Support for Social Policy by Age (Generational Warfare?) 140

TABLES

1.1 The Relative Size of the American Welfare State (1997) 15

1.2 Smaller Slice, Bigger Pie 24

2.1 Major Programs of the American Welfare State 31

2.2 Cracks in the Tiers (Part 1) 42

2.3 Cracks in the Tiers (Part 2) 47

3.1 Timing of Major New Social Programs during the Twentieth Century 61-62

3.2 Political Parties and New Social Programs in the Twentieth Century 67

4.1 Policy Innovation under Divided Government 75

5.1 Chronology of Medicaid and EITC Expansion 97

6.1 U.S. Public Opinion in Comparative Perspective 113-14

9.1 Race and Welfare Policy in the American States 187

9.2 Race and Medicaid Policy in the American States 189

9.3 Race and Unemployment Insurance in the American States 190

10.1 Support for Redistribution in the United States 199

10.2 Acceptable Income Inequality in Four Nations 202 
